\title{
Low Power and Area Optimized Architectures for BPSK Modulator
}

\author{
Usha S.M. \\ JSS Academy of Technical Education/ECE Dept, Bengaluru, 560 060, India \\ E-mail: ushasmjss@gmail.com \\ Mahesh H.B. \\ PESCE, Bengaluru, 560 050, India \\ E-mail: hbmahesh@pes.edu
}

Received: 07 September 2018; Accepted: 24 September 2018; Published: 08 December 2018

\begin{abstract}
Low power modulators are most efficient for wireless communication. The conventional BPSK modulator consumes more power and area. In this work, the new approaches for BPSK modulator are discussed and recorded. The four new approaches consume less area and power than the conventional design of BPSK Modulator. The power and area consumed by new approaches are compared with the conventional method. Cadence software is used for the simulation and synthesis, the power and area reduction in $180 \mathrm{~nm}, 90 \mathrm{~nm}$ and $45 \mathrm{~nm}$ CMOS Technology is reported, MATLAB/SIMULINK is used to do BER analysis of BPSK modulator with AWGN channel. The new architectures enhance the performance of BPSK Modulator in consuming less power and utilizing less area than the conventional design.
\end{abstract}

Index Terms-BPSK, QPSK, BOOTH MULTIPLIER, RTL, Cadence, CMOS, BER, Costas Loop.

\section{INTRODUCTION}

The transmission of digital information through the analog channel is addressed as digital communication. The modification of the carrier in consequently with the information signal is named as modulation. Phase Shift Keying is the adaptation of carrier parameters according to the information signal. The Binary Phase Keying (BPSK), Quadrature Phase Shift keying (QPSK) and Quadrature Amplitude Modulation (QAM) are the phase shift keying methods used in the digital communication.. BPSK modulation technique is generally used in wireless communication for its simple structural design of transmitter and receiver. In this paper an improved architectural design of the BPSK modulator is presented. This work aims at refining the existing design by reducing the hardware requirement and optimizing resource utilization in the design of BPSK modulator.

The BPSK is thought to be powerful modulation strategy in variance with the QPSK as the receiving system of BPSK is elementary to recollect the original information bits. BPSK demodulator needs only two decision points to recover the original data. BPSK can attain higher distance from the base station to mobile users in comparability with the QPSK. QPSK transmits more bits than BPSK, but it is highly susceptible to errors than BPSK. This paper is carved up into five sections. In Section-1 digital modulation schemes, benefits of BPSK over QPSK are presented. In Section-2 the types of modulators that are to be discussed in the next incisions are elaborated in depth. The conventional BPSK modulator design and its working is expressed in Section3. BPSK modulator with Booth Algorithm architecture is presented in Section-4. This section represents the working of each block of new architecture of BPSK and also informs how this new architecture assists in reducing hardware requirement of BPSK digital system in comparison with the existing BPSK digital design. BPSK Modulator with Iterative Algorithm is talked over with block diagram and flow-chart in Section-5. In section-6, a simplified architecture for BPSK Modulator is recorded. The design of the new BPSK modulator's architecture is carried out using Verilog hardware description language and CADENCE software is used for simulation and synthesis. Finally results of all modulators are exhibited in the Section-7, which confirms this new designs are functioning and can create BPSK modulated signal. The section- 8 details about the comparison and analysis of new architecture with the conventional design. The comparison shows that the new architecture consumes less power and area than the conventional architecture. Section-9 details about the Bit Error Rate analysis (BER) analysis of BPSK modulator on AWGN channel. BER analysis is performed for various values of Eb/No. Section-10 exhibit the implementation of Digital Costas loop using BPSK modulator. Section-11 describes the Simulation Results of BPSK with Costas Loop to retrieve the message signal after demodulation.

\section{MODUlators}

The BPSK modulator discussed in earlier work are reported with more power consumption. The following low power consumed BPSK modulators are discussed and compared in this paper. 
1. Conventional BPSK Modulator.

2. BPSK Modulator with Booth Algorithm.

3. BPSK Modulator using Iterative algorithm.

4. Proposed BPSK Modulator-3.

5. BER Analysis using BPSK Modulator \& Demodulator over AWGN channel.

6. BPSK receiver with Costas Loop.

\section{CONVENTIONAL BPSK MODULATOR}

BPSK is a Bi-phase modulation method, where the zeroes and ones in a binary message are comprised by two dissimilar phase values. The base functions are impertinent to each other. The modulation is attained by varying the phase of the sinusoidal signal based on the message bits.

$$
\begin{aligned}
& S_{1}(t)=A c \cos \left(2 \pi f_{c} t\right), \quad 0 \leq t \leq T b \text { for binary } 1 \\
& S_{0}(t)=A c \cos \left(2 \pi f_{c} t+\pi\right), \quad 0 \leq t \leq T b \text { for binary } 0
\end{aligned}
$$

Where, Ac is the amplitude of the signal.

fc is the carrier frequency.

$\mathrm{Tb}$ is the bit period in seconds.

$\mathrm{S}_{0}(\mathrm{t})$ stands for the carrier signal, when message signal $\mathrm{m}(\mathrm{t})=$ ' 0 ' is propagated.

$\mathrm{S}_{1}(\mathrm{t})$ stands for the carrier signal, when information bit $\mathrm{m}(\mathrm{t})=$ ' 1 ' is propagated.

\section{A. Conventional BPSK Transmitter}

The Binary data is enforced to Encoder block. The data is converted to NRZ format. The carrier sine wave generated by local oscillator is applied to the multiplier block with the NRZ output to originate the BPSK Modulated output as depicted in Fig. 1.

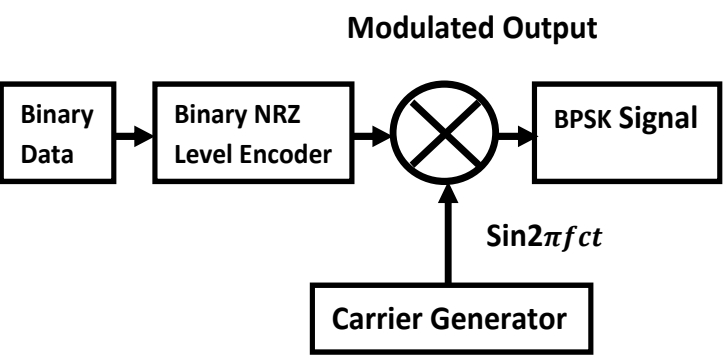

Fig.1. Conventional BPSK Modulator.

\section{B. Conventional BPSK Receiver}

A conventional BPSK demodulator is indicated in Fig.2. The BPSK demodulator comprises of mixer, band pass filter and detector. The modulated BPSK signal is multiplied on the carrier signal originated by the local oscillator. The signal is band limited and enforced to the detector. A detector makes a conclusion on each bit based on a threshold to create the Message Signal.

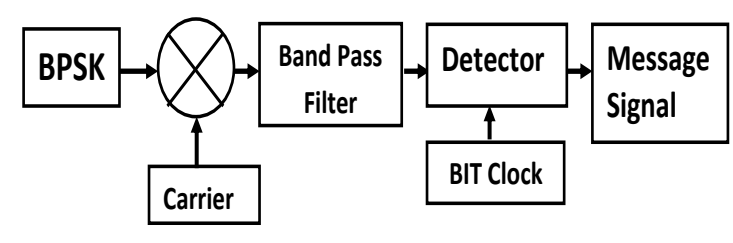

Fig.2. BPSK Demodulator

\section{PROPOSED BPSK MODULATOR WITH BOOTH ALGORITHM}

The BPSK Modulator with Booth algorithm is as shown below in Fig. 3. The conventional multiplier is replaced with the Booth multiplier. The encoder output and sine data are enforced to the Booth Multiplier. The rendered output results with the BPSK signal. The Power, Area and Gate requirement report of Proposed BPSK Modulator with Booth algorithm in 180nm, 90nm and $45 \mathrm{~nm}$ CMOS technology is interpreted in Table 1.

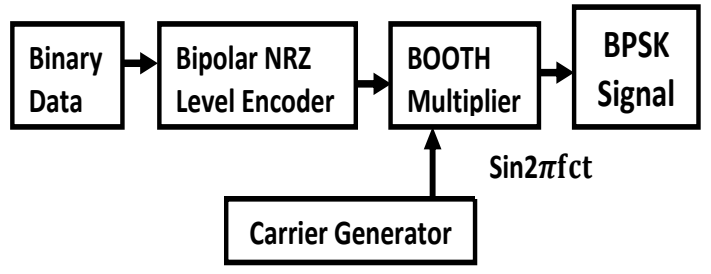

Fig.3. BPSK Modulator with Booth Multiplier.

The implementation of BPSK using Booth multiplier is as pictured below in Fig. 4. If the input bit stream is 10, the phase data is subtracted from the product register and arithmetic right shift is executed, if the input bit stream is 01 , the phase data is appended to the product register and arithmetic right shift is carried out. If the input bit stream is 00 or 11 , directly the arithmetic right shift is attained on the data.

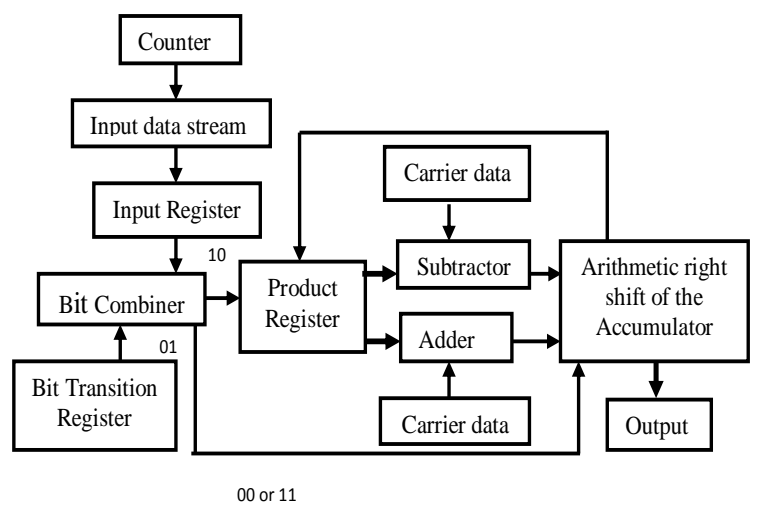

Fig.4. BPSK Modulator with Booth Multiplier.

\section{BPSK MODULATOR WITH ITERATIVE ALGORITHM}

An iterative algorithm is employed to yield digital sine and cosine waves. The block diagram below in "Fig. 5," designates the implementation of iterative algorithm. 
Sine and Cosine values are calculated using this knowledge and computed values are placed in sine_reg and cos_reg respectively, as shown in the flowchart below in Fig. 6. The generated sine and cosine values are allowed to the modulator block. The information data stream is procreated with the carrier data to bring forth the BPSK.

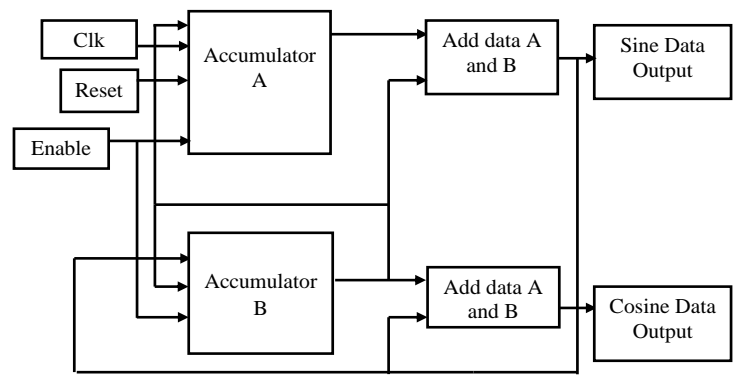

Fig.5. Block diagram depicts the Implementation of iterative algorithm.

In first step, clock, reset and enable pins are initialized, sine and cosine registers are affirmed with two integers $m$ and $\mathrm{n}$. If the clock and reset are enabled, then sine and cosine values are computed. If clock and reset are disabled, then sine and cosine registers are stored with the initial values.

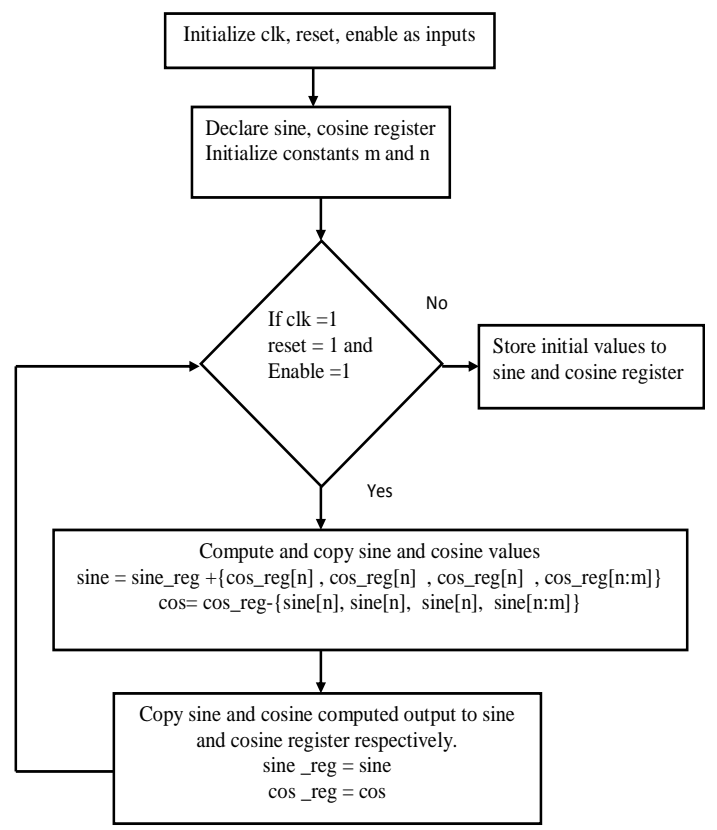

Fig.6. Flow chart shows sine and cosine generation using proposed Iterative algorithm-2.

\section{PROPOSED BPSK MODULATOR-3}

The proposed BPSK Modulator-3 is revealed below in Fig 7. It is the simplified block diagram. It comprises of selector and control block. Initially the digital carrier data generated from the above blocks are stored in memory, Later the carrier phase data is picked out accordingly with the input data.

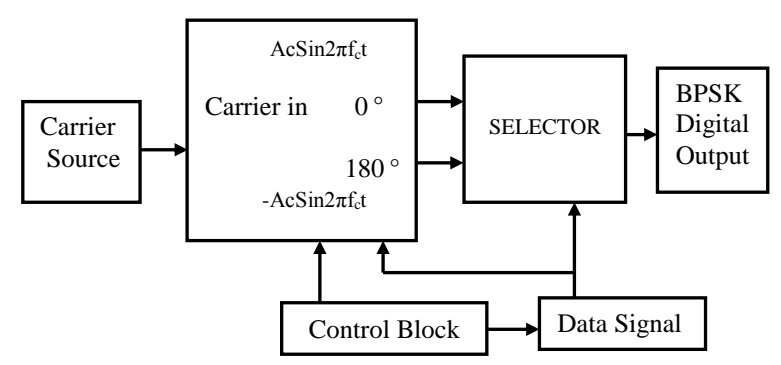

Fig.7. Proposed BPSK Modulator-3.

\section{RESULTS}

\section{A. Conventional BPSK Modulator}

The results of conventional BPSK modulator are represented in Table 1, below. The Table details about Leakage Power and Dynamic power. The total power is the addition of dynamic and leakage Power. The total power in $\mathrm{nW}$ and area in $\mathrm{um}^{2}$ is comprised in $180 \mathrm{~nm}$, $90 \mathrm{~nm}$ and $45 \mathrm{~nm}$ CMOS technology. The power consumption is reported as $174059 \mathrm{nW}, 52432 \mathrm{nW}$ and $12083 \mathrm{nW}$ in $180 \mathrm{~nm}, 90 \mathrm{~nm}$ and $45 \mathrm{~nm}$ CMOS technology respectively. The area utilized is covered as $8968 \mu \mathrm{m}^{2}$, $2894 \mu \mathrm{m}^{2}$ and $692 \mu \mathrm{m}^{2}$ in $180 \mathrm{~nm}, 90 \mathrm{~nm}$ and $45 \mathrm{~nm}$ respectively. The area and power requirement decreases with the technology.

Table 1. Power and Area Report of conventional BPSK Modulator

\begin{tabular}{|c|c|c|c|c|c|}
\hline Technology & Cells & $\begin{array}{c}\text { Leakage } \\
\text { Power(nW) }\end{array}$ & $\begin{array}{c}\text { Dynamic } \\
\text { Power(nW) }\end{array}$ & $\begin{array}{c}\text { Total } \\
\text { Power } \\
(\mathbf{n W})\end{array}$ & $\begin{array}{c}\text { Total } \\
\mathbf{A r e a} \\
\boldsymbol{\mu m}^{\mathbf{2}}\end{array}$ \\
\hline $180 \mathrm{~nm}$ & 477 & 219.784 & 173840.05 & $\mathbf{1 7 4 0 5 9}$ & $\mathbf{8 9 6 8}$ \\
\hline $90 \mathrm{~nm}$ & 476 & 11719.097 & 40713.10 & $\mathbf{5 2 4 3 2}$ & $\mathbf{2 8 9 4}$ \\
\hline $45 \mathrm{~nm}$ & 448 & 354.211 & 11729.458 & $\mathbf{1 2 0 8 3}$ & $\mathbf{6 9 2}$ \\
\hline
\end{tabular}

\section{B. BPSK Modulator with Booth Algorithm}

The results of BPSK Modulator with Booth Algorithm in $180 \mathrm{~nm}, 90 \mathrm{~nm}$ and $45 \mathrm{~nm}$ are detailed in Table 2. The power consumption is accounted as $86165.7 \mathrm{nW}$, $22260.2 \mathrm{nW}$ and $3848.8 \mathrm{nW}$ in $180 \mathrm{~nm}, 90 \mathrm{~nm}$ and $45 \mathrm{~nm}$ CMOS technology respectively. The area utilized is described as $1869 \mu \mathrm{m}^{2}, 584 \mu \mathrm{m}^{2}$ and $146 \mu \mathrm{m}^{2}$ in $180 \mathrm{~nm}$, $90 \mathrm{~nm}$ and $45 \mathrm{~nm}$ respectively.

Table 2. Power and Area Report of BPSK Modulator with Booth Algorithm

\begin{tabular}{|c|c|c|c|c|c|}
\hline Technology & Cells & $\begin{array}{c}\text { Leakage } \\
\text { Power } \\
(\mathrm{nW})\end{array}$ & $\begin{array}{c}\text { Dynamic } \\
\text { Power } \\
(\mathrm{nW})\end{array}$ & $\begin{array}{c}\text { Total } \\
\text { Power } \\
(\mathbf{n W})\end{array}$ & $\begin{array}{c}\text { Total } \\
\text { Area } \\
\boldsymbol{\mu m}^{2}\end{array}$ \\
\hline $180 \mathrm{~nm}$ & 120 & 53 & 86112.6 & $\mathbf{8 6 1 6 5 . 7}$ & $\mathbf{1 8 6 9}$ \\
\hline $90 \mathrm{~nm}$ & 134 & 2222.7 & 20037.5 & $\mathbf{2 2 2 6 0 . 2}$ & $\mathbf{5 8 4}$ \\
\hline $45 \mathrm{~nm}$ & 139 & 80.5 & 3765.2 & $\mathbf{3 8 4 5 . 8}$ & $\mathbf{1 4 6}$ \\
\hline
\end{tabular}

\section{BPSK Modulator using Iterative Algorithm}

The results of BPSK Modulator using Iterative Algorithm are covered in Table 3 below. The total power in $\mathrm{nW}$ and area in $\mu \mathrm{m}^{2}$ in $180 \mathrm{~nm}, 90 \mathrm{~nm}$ and $45 \mathrm{~nm}$ CMOS technology is pointed below in Table. 3. The total power 
consumed by using this approach is $231214.0 \mathrm{nW}$, $58868.6 \mathrm{nW}$ and $8033.8 \mathrm{nW}$ respectively in $180 \mathrm{~nm}, 90 \mathrm{~nm}$ and $45 \mathrm{~nm}$ CMOS technology. The total area utilized using this method is $4847 \mu \mathrm{m}^{2}, 1505 \mu \mathrm{m}^{2}$ and $432 \mu \mathrm{m}^{2}$ in $180 \mathrm{~nm}, 90 \mathrm{~nm}$ and $45 \mathrm{~nm}$ CMOS technology respectively.

Table 3. Power and Area Report of BPSK Modulator with Iterative algorithm

\begin{tabular}{|c|c|c|c|c|c|}
\hline Technology & Cells & $\begin{array}{c}\text { Leakage } \\
\text { Power } \\
(\mathrm{nW})\end{array}$ & $\begin{array}{c}\text { Dynamic } \\
\text { Power } \\
(\mathrm{nW})\end{array}$ & $\begin{array}{c}\text { Total } \\
\text { Power } \\
(\mathbf{n W})\end{array}$ & $\begin{array}{c}\text { Total } \\
\mathbf{A r e a}^{2} \\
\boldsymbol{\mu m}^{2}\end{array}$ \\
\hline $180 \mathrm{~nm}$ & 151 & 149.8 & 231064.6 & $\mathbf{2 3 1 2 1 4 . 0}$ & $\mathbf{4 8 4 7}$ \\
\hline $90 \mathrm{~nm}$ & 139 & 8058.0 & 50810.5 & $\mathbf{5 8 8 6 8 . 6}$ & $\mathbf{1 5 0 5}$ \\
\hline $45 \mathrm{~nm}$ & 173 & 242.0 & 7791.8 & $\mathbf{8 0 3 3 . 8}$ & $\mathbf{4 3 2}$ \\
\hline
\end{tabular}

\section{Proposed BPSK Modulator-3}

Table 4. Power and Area Report BPSK Modulator with Proposed Algorithm-3

\begin{tabular}{|c|c|c|c|c|c|}
\hline Technology & Cells & $\begin{array}{c}\text { Leakage } \\
\text { Power } \\
(\mathrm{nW})\end{array}$ & $\begin{array}{c}\text { Dynamic } \\
\text { Power } \\
(\mathrm{nW})\end{array}$ & $\begin{array}{c}\text { Total } \\
\text { Power } \\
(\mathbf{n W})\end{array}$ & $\begin{array}{c}\text { Total } \\
\mathbf{A r e a}^{2} \\
\boldsymbol{\mu m}^{\mathbf{2}}\end{array}$ \\
\hline $180 \mathrm{~nm}$ & 7 & 6.2 & 4882 & $\mathbf{4 8 8 8 . 3}$ & $\mathbf{1 8 3}$ \\
\hline $90 \mathrm{~nm}$ & 8 & 301.9 & 1200 & $\mathbf{1 5 0 2 . 0}$ & $\mathbf{5 7}$ \\
\hline $45 \mathrm{~nm}$ & 9 & 9.3 & 329 & $\mathbf{3 3 8 . 3}$ & $\mathbf{1 6}$ \\
\hline
\end{tabular}

The power consumption and area utilization of BPSK modulator with projected architecture- 3 is elaborated in Table 4 . The total power consumed using this approach in 180nm, 90nm and 45nm CMOS technology respectively as $488.3 \mathrm{nW}, 1502 \mathrm{nW}$ and $383.3 \mathrm{nW}$. The total area utilized using this approach in $180 \mathrm{~nm}, 90 \mathrm{~nm}$ and $45 \mathrm{~nm}$ technology is $183 \mu \mathrm{m}^{2}, 57 \mu \mathrm{m}^{2}$ and $16 \mu \mathrm{m}^{2}$ respectively.

\section{COMPARISON AND ANALYSIS}

The results obtained by each method are tabulated and compared. The following parameters of proposed approaches are compared with the conventional method.

1. Device utilization summary.

2. Power Consumption Report

3. Area Utilization Report

\section{A. Device utilization Summary}

The device utilized (LUTs and slices) by suggested approaches are compared with the conventional method. As elaborated in Table 5, the conventional method uses 98 LUTs and 57 slices. The proposed approaches use minimum LUTs and slices than the conventional method. BPSK Modulator with Booth algorithm uses 74 LUTs and 39 slices. The BPSK Modulator using iterative algorithm uses 57 LUTs and 33 slices. Proposed BPSK Modulator-3 uses one-4 inputs LUT and 1-slice. The last method utilizes minimum logic blocks. The Table 5 is pictured in Fig.8, below with bar graph.

Table 5. Device utilization Summary of Conventional and proposed BPSK modulators

\begin{tabular}{|c|c|c|c|c|}
\hline Logic Utilization & $\begin{array}{c}\text { Convention } \\
\text { al BPSK } \\
\text { Modulator }\end{array}$ & $\begin{array}{c}\text { Proposed } \\
\text { BPSK } \\
\text { Modulator with } \\
\text { Booth algorithm }\end{array}$ & $\begin{array}{c}\text { BPSK } \\
\text { Modulator using } \\
\text { Iterative algorithm }\end{array}$ & $\begin{array}{c}\text { Proposed } \\
\text { BPSK } \\
\text { Modulator } \\
-3\end{array}$ \\
\hline slides & 57 & 39 & 33 & 1 \\
\hline Slice Flip Flops & 48 & & 40 & 1 \\
\hline 4 input LUTs & 98 & 74 & 57 & 37 \\
\hline Number of IOs & 20 & 25 & 28 & 37 \\
\hline bonded IOBs & 20 & 25 & 28 & 3 \\
\hline IOB Flip Flops & 1 & & & 1 \\
\hline GCLKs & 1 & & 1 & \\
\hline
\end{tabular}

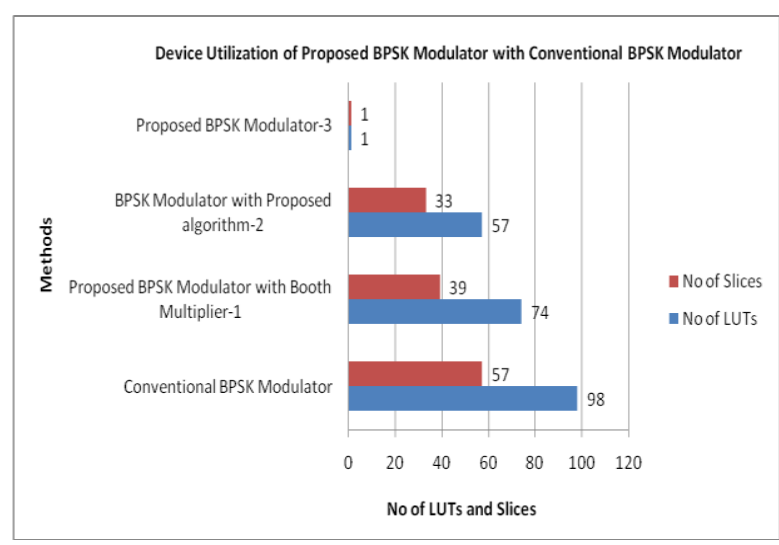

Fig.8. Device utilization summary.

\section{B. Power Consumption Report}

Table 6. Power comparison of conventional BPSK modulator with proposed BPSK modulator in $180 \mathrm{~nm}, 90 \mathrm{~nm}$ and $45 \mathrm{~nm}$ technology

\begin{tabular}{|c|c|c|c|c|}
\hline BPSK & $\begin{array}{c}\text { Conventiona } \\
\text { 1 BPSK } \\
\text { Modulator } \\
\text { Power } \\
(\mathrm{nW})\end{array}$ & $\begin{array}{c}\text { Proposed } \\
\text { BPSK } \\
\text { Modulator } \\
\text { with Booth } \\
\text { algorithm } \\
\text { Power(nW) }\end{array}$ & $\begin{array}{c}\text { BPSK } \\
\text { Modulator } \\
\text { using } \\
\text { Iterative } \\
\text { algorithm } \\
\text { Power(nW) }\end{array}$ & $\begin{array}{c}\text { Proposed } \\
\text { BPSK } \\
\text { Modulator-3 } \\
\text { Power(nW) }\end{array}$ \\
\hline $180 \mathrm{~nm}$ & 174059.836 & 86165.696 & 231214.421 & 4888.261 \\
\hline $90 \mathrm{~nm}$ & 52432.198 & 22260.198 & 58868.566 & 1502.034 \\
\hline $45 \mathrm{~nm}$ & 12083.669 & 3845.788 & 8033.803 & 338.383 \\
\hline
\end{tabular}


The power comparison of conventional BPSK modulator with proposed BPSK modulator in $180 \mathrm{~nm}$, $90 \mathrm{~nm}$ and $45 \mathrm{~nm}$ CMOS technology is rendered in Table 6 The power consumption is minimum in suggested BPSK modulators in comparing with the conventional BPSK modulator.

The power consumed by BPSK modulators is pictured in bar graph below in Fig. 9. The power consumed in conventional BPSK method is $174059.836 \mathrm{nW}$, $52432.198 \mathrm{nW}$ and $12083.669 \mathrm{nW}$ in $180 \mathrm{~nm}, 90 \mathrm{~nm}$ and $45 \mathrm{~nm}$ CMOS technology respectively. The power consumed by BPSK Modulator with Booth algorithm is 86165.696nW 22260.198nW and 3845.788nW in $180 \mathrm{~nm}$, $90 \mathrm{~nm}$ and $45 \mathrm{~nm}$ respectively. The power consumed by BPSK Modulator with Iterative algorithm is 231214.421nW, 58868.566nW and 8033.803nW in $180 \mathrm{~nm}, 90 \mathrm{~nm}$ and $45 \mathrm{~nm}$ technology respectively. Finally the power consumed by proposed BPSK Modulator-3 is $4888.261 \mathrm{nW}, 1502.034 \mathrm{nW}$ and $338.383 \mathrm{nW}$ in $180 \mathrm{~nm}$, $90 \mathrm{~nm}$ and $45 \mathrm{~nm}$ technology respectively. As shown in bar graph the power consumed by proposed Iterative algorithm is higher than the conventional BPSK Modulator. The other two proposed approaches consume minimum power than the conventional BPSK Modulator.

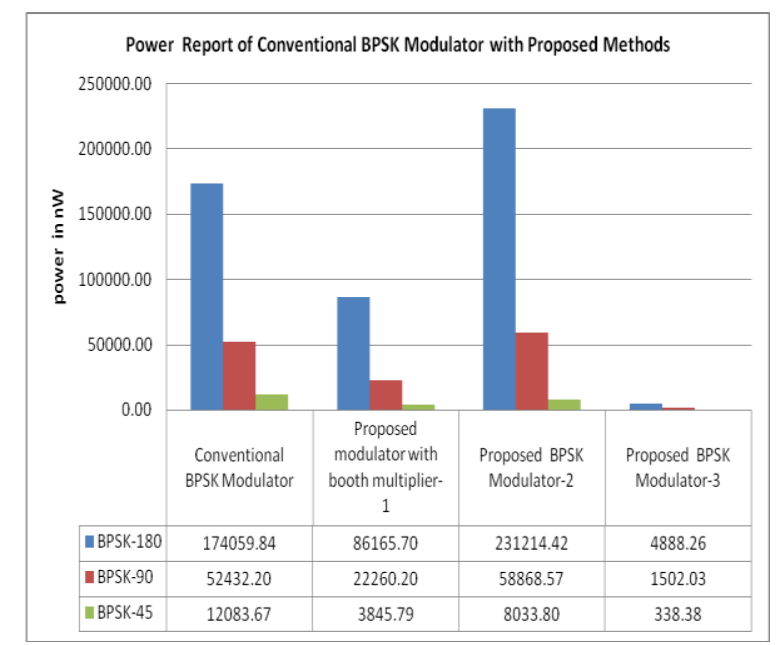

Fig.9. Power consumption report of conventional modulator with other proposed modulators.

\section{Area Utilization Report}

The conventional BPSK utilizes more area than the proposed BPSK modulators. Comparatively the BPSK modulator-3 utilizes minimum area than the other modulators. The area utilized by conventional BPSK Modulator is $8968 \mu \mathrm{m}^{2}, 2878 \mu \mathrm{m}^{2}$ and $692 \mu \mathrm{m}^{2}$.

The proposed BPSK Modulator with Booth algorithm utilizes $1869 \mu \mathrm{m}^{2}, 584 \mu \mathrm{m}^{2}$ and $146 \mu \mathrm{m}^{2}$. The BPSK modulator using Iterative algorithm utilizes $4847 \mu \mathrm{m} 2$, $1505 \mu \mathrm{m} 2$ and $432 \mu \mathrm{m}^{2}$. The area employed by proposed BPSK modulator-3 is $183 \mu \mathrm{m}^{2}, 57 \mu \mathrm{m}^{2}$ and $16 \mu \mathrm{m}^{2}$ as depicted in Table 7 . The synthesis carried out in $180 \mathrm{~nm}$, 90nm and 45nm CMOS technology respectively.
Table 7. Area Report of BPSK Modulator with Proposed Algorithm-2

\begin{tabular}{|c|c|c|c|c|}
\hline BPSK & $\begin{array}{c}\text { Convention } \\
\text { al BPSK } \\
\text { Modulator } \\
\text { Area } \mu \mathrm{m} 2\end{array}$ & $\begin{array}{c}\text { Proposed } \\
\text { BPSK } \\
\text { Modulator } \\
\text { with Booth } \\
\text { algorithm } \\
\text { Area } \mu \mathrm{m}^{2}\end{array}$ & $\begin{array}{c}\text { BPSK } \\
\text { Modulator } \\
\text { Using Iterative } \\
\text { algorithm } \\
\text { Area } \mu \mathrm{m}^{2}\end{array}$ & $\begin{array}{c}\text { Proposed } \\
\text { BPSK } \\
\text { Modulator-3 } \\
\text { Area } \mu \mathrm{m}^{2}\end{array}$ \\
\hline $180 \mathrm{~nm}$ & 8968 & 1869 & 4847 & 183 \\
\hline $90 \mathrm{~nm}$ & 2878 & 584 & 1505 & 57 \\
\hline $45 \mathrm{~nm}$ & 692 & 146 & 432 & 16 \\
\hline
\end{tabular}

The Table 7 is pictured in bar graph below in Fig. 10. The proposed BPSK modulator using Iterative algorithm utilizes maximum area than the other proposed methods.

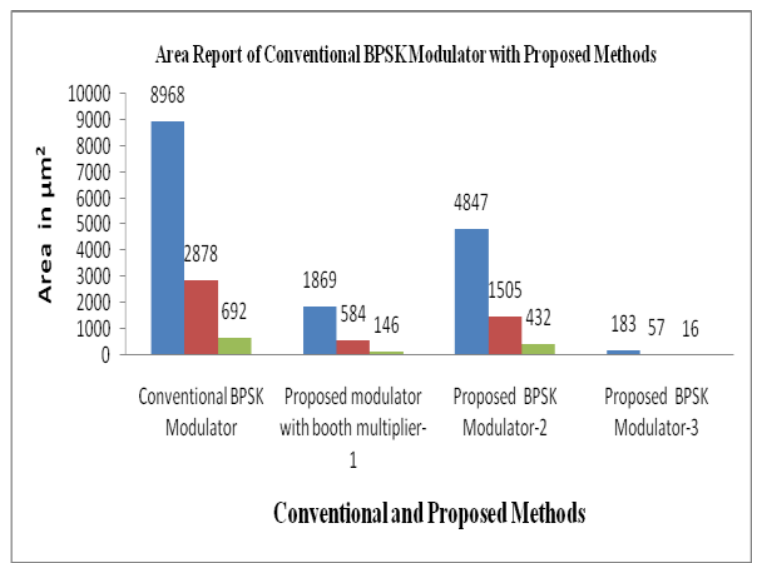

Fig.10. Area utilization report of conventional modulator with other proposed modulators.

\section{BPSK MODULATOR WITH AWGN CHANNEL}

The information data is transmitted over AWGN channel. The data is toned using BPSK modulator and transmitted over AWGN channel and extracted by BPSK demodulator as shown in Fig.11. The BER (Bit Error Rate) analysis for various values of Eb/No is carried out and results are indicated in Table 8 , below.

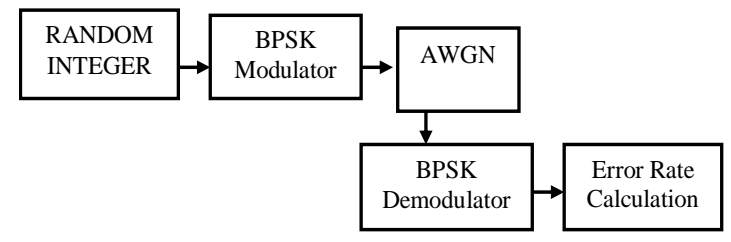

Fig.11. BER Analysis of BPSK Modulator over AWGN channel.

Table 8. Eb/No. Vs. Bit Error Rate Analysis.

\begin{tabular}{|c|c|c|}
\hline Sl.No & Eb/N0 & BER \\
\hline 1 & 0 & 0.09524 \\
\hline 2 & 2 & 0 \\
\hline 3 & 5 & 0 \\
\hline 4 & 10 & 0 \\
\hline 5 & 30 & 0 \\
\hline
\end{tabular}


The Eb/No Versus Bit Error Rate analysis is carried out over AWGN channel using BPSK modulator and demodulator is indicated in Table 8 , as the Eb/No step-ups, bit error rate diminishes.

As depicted below in Fig. 12. When $\mathrm{Eb} / \mathrm{No}$ is $0 \mathrm{~dB}$, the error rate is 0.09524 , when $\mathrm{Eb} / \mathrm{No}$ increases from $0 \mathrm{~dB}$ to $30 \mathrm{~dB}$, in steps of $5 \mathrm{~dB}$. The error rate minimizes.

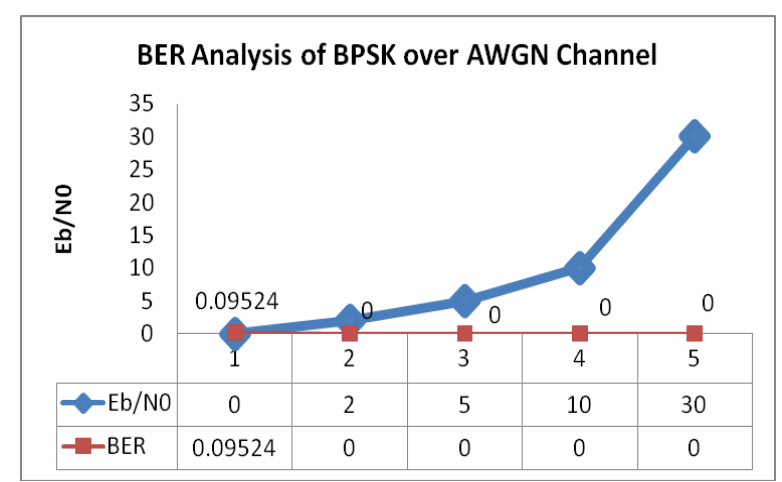

Fig.12. BPSK Modulator over AWGN Channel

\section{IMPLEMENTATION OF Digital COSTAS LOOP}

A Costas loop is a phase locked loop based circuit, which is used for carrier frequency recovery from suppressed carrier modulation signals. The main disadvantage of BPSK is that there will be phase errors in the received signal at the receiver end. To check the effective working of the receiver, a transmitter is designed. The design of the transmitter includes capturing an audio signal, sampling it and converting it into a digital signal, encoding it into a PN-sequence and modulating it using BPSK modulation technique. The transmitter section is depicted below in Fig. 13.

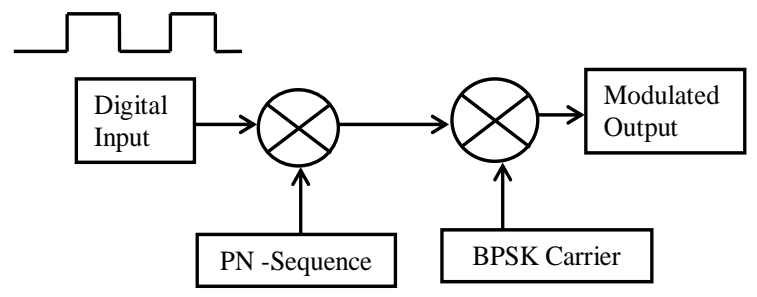

Fig.13. BPSK Transmitter with PN-Sequence.

At the receiver end, the BPSK signal received is demodulated as revealed in the Fig. 14, below.

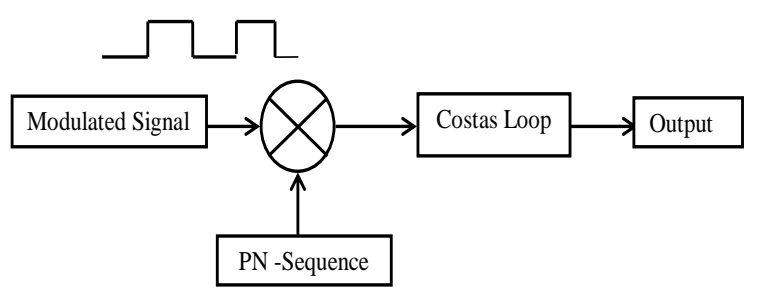

Fig.14. BPSK Receiver with Costas Loop.

Costas loop involves two parallel crossing loops working together from the same Numerically-Controlled
Oscillator (NCO). The primary loop is I arm, which uses the NCO as in a Phase Locked Loop (PLL) and the second, Q arm uses a 90 degree tilted NCO signal. I and Q combiner outputs are filtered by single pole Butterworth low pass filter. I and Q arm channel outputs are multiplied together and the result is scaled and filtered to produce the loop error. This loop error is used to control the NCO. The loop error should settle to a value when the loop is locked. A negative loop error decreases the NCO increment resulting in a lower NCO frequency and a positive loop error increases the $\mathrm{NCO}$ increment resulting in a higher NCO frequency. The architectural level block diagram is as shown in the Fig. 15, below.

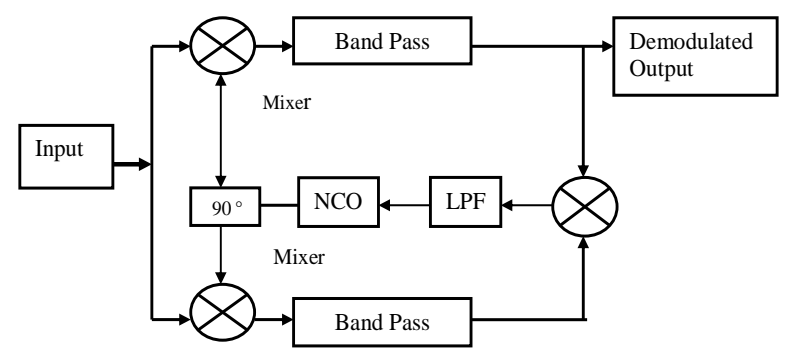

Fig.15. Architectural level block diagram of Costas loop.

\section{Simulation Results}

The BPSK modulated signal is projected in Fig. 16. When the information bit is binary 0 , the phase of the carrier is not varying. When the information bit is 1 the phase reversal is 180 degree. The phase modulated BPSK signal is generated.

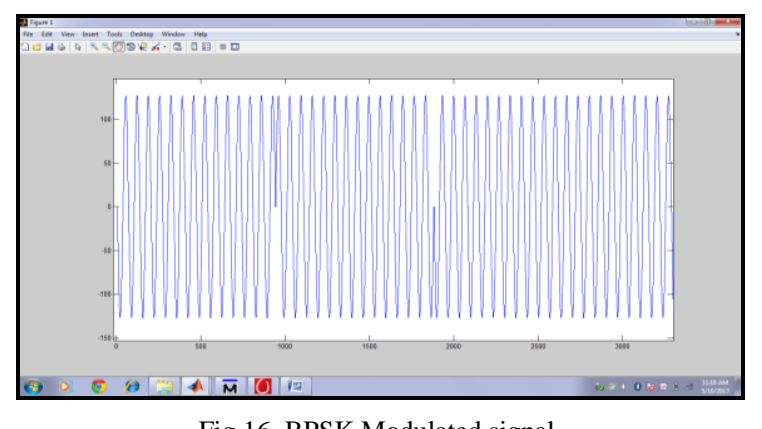

Fig.16. BPSK Modulated signal.

Fig.17. Below shows recovered message signal after demodulation.

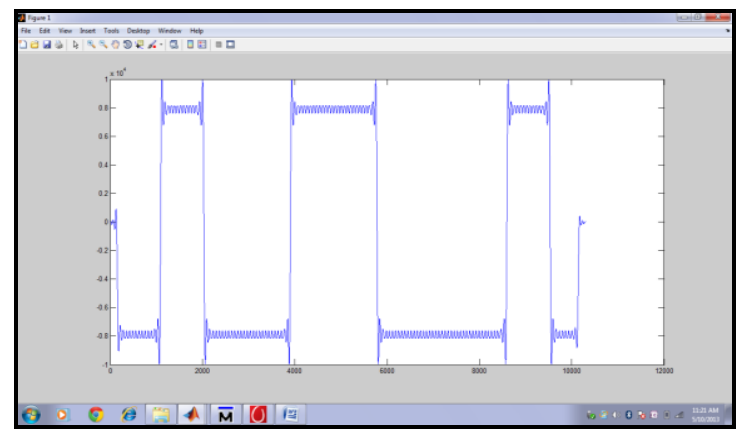

Fig.17. Message signal after demodulation. 
The receiver can easily detect the message signal, whenever there is a change in the phase. The BPSK modulated message signal, the demodulated and filtered output is depicted in Fig. 18.

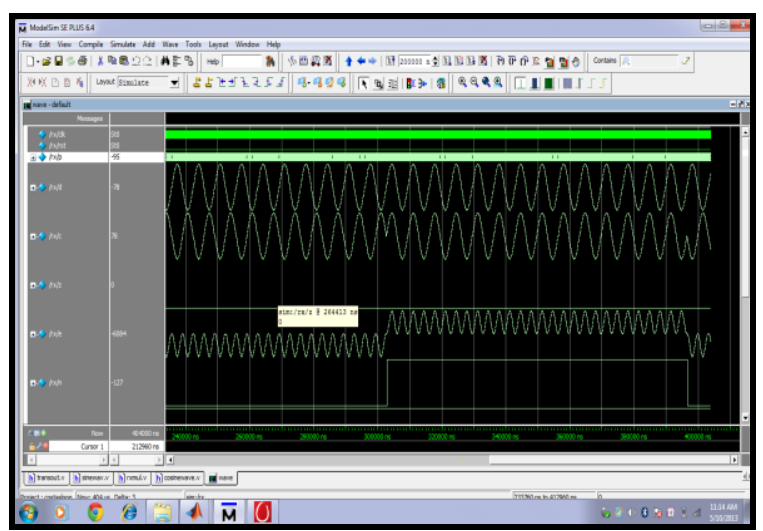

Fig.18. BPSK modulated message signal, the demodulated and filtered output.

\section{CONCLUSION}

In this paper, new approaches for BPSK modulators are suggested. The area utilized and power consumed by new BPSK modulator architectural designs are compared with the existing conventional BPSK modulator and revealed that BPSK modulator using Booth Multiplier and proposed BPSK Modulator-3 consumes minimum power than the conventional BPSK method. The area and device utilization in proposed approaches is reduced in comparison with the conventional method. The simulation and synthesis is carried by using CADENCE tool. The work is carried out in $180 \mathrm{~nm}, 90 \mathrm{~nm}$ and $45 \mathrm{~nm}$ CMOS technologies. The results are tabulated and compared and proved that the new approaches are efficient than the conventional technique in terms of power and area.

\section{ACKNOWLEDGMENT}

I wholeheartedly thank my college JSS Academy of technical education for providing me a lab facility to carry out this work.

\section{REFERENCES}

[1] U. Raza, P. Kulkarni, and M. Sooriyabandara, "Low Power Wide Area Networks: An Overview," IEEE Communications Surveys Tutorials, vol. PP, no. 99, pp. $1-1,2017$.

[2] Rasoul Moradi, Ebrahim Farshidi Mohammad Soroosh, A low power passive-active $\Delta \Sigma$ modulator with highresolution employing an integrator with open-loop unitygain buffer", Department of Electrical, Faculty of Engineering, Shahid Chamran University of Ahvaz, Ahvaz, Iran, sep 2018.

[3] H. P. Enterprise, "Low Power Wide Area (LPWA) Networks Play an Important Role in Connecting a Range of Devices," Business white paper, November 2016.

[4] M. R. Palattella, M. Dohler, A. Grieco, G. Rizzo, J.
Torsner, T. Engel, and L. Ladid, "Internet of Things in the 5G Era: Enablers, Architecture, and Business Models," IEEE Journal on Selected Areas in Communications, vol. 34, no. 3, pp. 510-527, March 2016.

[5] Y. Roth, J.-B. Dor'e, L. Ros, and V. Berg, "Turbo-FSK, a Physical Layer for Low-Power Wide-Area Networks: Analysis and Optimization," Elsevier Comptes Rendus Physique, vol. 18, no. 2, pp. 178 - 188, 2017.

[6] "LTE Evolved Universal Terrestrial Radio Access (EUTRA): Physical Channels and Modulation," 3GPP TS 36.211, V13.2.0, Release 13, Aug 2016.

[7] Y. Roth, "The Physical Layer for Low Power Wide Area Networks: A Study of Combined Modulation and Coding Associated with an Iterative Receiver," $\mathrm{PhD}$ Thesis, University Grenoble Alpes, Jul. 2017.

[8] Y. Roth, J.-B. Dor'e, L. Ros, and V. Berg, "5G Contender Waveforms for Low Power Wide Area Networks in a 4G OFDM Framework," in 2018 25th International Conference on Telecommunications (ICT) (ICT 2018), Saint Malo, France, Jun. 2018.

[9] Azad Mahmoudi, PooyaTorkzadeh, Massoud Dousti, "A study of analog decision feedback equalization for ADCBased serial link receivers", Department of Electrical and Computer Engineering, Science and Research Branch, Islamic Azad University, Tehran, Iran, Sept. 2018.

[10] Yoann_Roth, Jean-Baptiste_Doré, Laurent_Ros, “Coplanar Turbo-FSK: A Flexible and Power Efficient Modulation for the Internet-of-Things", Wireless Communications and Mobile Computing, August 2018.

[11] Y. E. Wang, X. Lin, A. Adhikary et al., "A Primer on 3GPP Narrowband Internet of Things," IEEE Communications Magazine, vol. 55, no. 3, pp. 117-123, 2017.

[12] Y. Roth, J.-B. Doré, L. Ros, and V. Berg, "EXIT chart optimization of turbo-FSK: application to low power wide area networks," in Proceedings of the 9th International Symposium on Turbo Codes Iterative Information Processing (ISTC '16), Brest, France, September 2016.

[13] M. R. Palattella, M. Dohler, A. Grieco et al., "Internet of things in the 5G Era: enablers, architecture, and business models," IEEE Journal on Selected Areas in Communications, vol. 34, no. 3, pp. 510-527, 2016.

[14] Jinting Wang, Linjie Zhou, Haike Zhu, Qianqian Wu, Rui Yang, Lei Liu, Tao Wang, and Jianping Chen, "Silicon high-speed BPSK modulator: design and optimization", Asia Communications and Photonics Conference 2014, OSA Technical Digest Optical Society of America, 2014.

[15] T. Rebbeck, M. Mackenzie, and N. Afonso, Low-Powered Wireless Solutions Have the Potential to Increase the M2M Market by Over 3 Billion Connections, Analysis Mason, 2014

[16] Asaraf Mohamed Moubark, Mohd Alauddin Mohd Ali," FPGA implementation of low power digital QPSK modulator using Verilog HDL",Journal of Applied Sciences, pp.385-392,ISSN 1812-5654, 2013.

[17] Hazrat Ali, Xianwei Zhou, Khalid Iqbal,"FPGA Architecture for OFDM, Software Defined Radio", IEEE Journal, 2013.

[18] Fanxin Zeng, Xiaoping Zeng, Zhenyu Zhang and Guixin Xuan, "New constructions of 16-QAM periodic complementary sequences" IEEE communications, letters, Vol. 16, no.12, pp 2040-2043, December 2012.

[19] Masud, A., Samsuzzaman, M., Rahman, M. A., "Bit Error Rate Performance Analysis on Modulation Techniques of Wideband Code Division Multiple Access" Journal of Telecommunications, Vol 1, Issue 2, 2010.

[20] Wenmiao Song, Jingying Zhang, Qiongqiong Yao, 
"Design And Implement Of BPSK Modulator And Demodulator Based On Modern DSP Technology," IEEE International Symposium. pp. 1135-1137, 2009.

[21] Y. Byungwook, H. L. Kyu and L. Chungyong, "Implementation of IEEE 802.16e MIMO-OFDMA Systems with K-BEST Lattice Decoding Algorithm", International Conference on Consumer Electronics. Las Vegas, NV, USA, 2007.

[22] Charles U. Ndujiuba, Oluyinka Oni, Augustus E. Ibhaze, "Comparative Analysis of Digital Modulation Techniques in LTE 4G Systems," Journal of Wireless Networking and Communications pp. 60-66, 2015.

\section{Authors' Profiles}

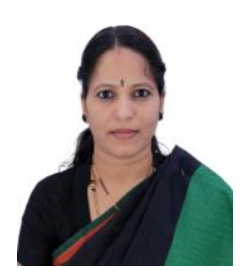

Dr. Usha S.M. from Bengaluru- Karnataka, India obtained B.E (Electronics \& Communication Engineering) Degree from Mysore University in the year 2000.

M.Tech in VLSI Design and Embedded Systems from VTU Belgaum in 2011 and Awarded Ph.D in Optimization and Performance Analysis of Digital Modulators form VTU Belgaum in the year 2017. She is currently working as a Associate Professor in JSS Academy of Technical Education, Bengaluru. Karnataka, India. She is member of professional Bodies such as IEEE, ISTE and MIE.

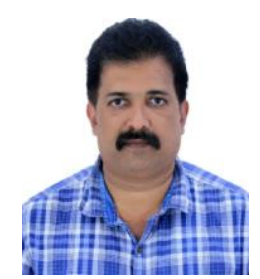

Mr. Mahesh H.B. from BengaluruKarnataka, India obtained Computer Science B.E, degree from Mysore University in the year 1996, M.Tech in Networking \& Internet Engineering from VTU in the year 2004. Currently, working as an Assistant Professor in PES University, Bengaluru, and Karnataka, India. $\mathrm{He}$ is member of professional bodies such as IEEE, CSE.

How to cite this paper: Usha S.M., Mahesh H.B., "Low Power and Area Optimized Architectures for BPSK Modulator", International Journal of Information Technology and Computer Science(IJITCS), Vol.10, No.12, pp.33-40, 2018. DOI: 10.5815/ijitcs.2018.12.05 